\title{
The Status Quo of College Students' Online Shopping Addiction and Its Coping Strategies
}

\author{
Jiahui Zhang ${ }^{1}$, Zhiqiang Bai ${ }^{1}$, Jingxia Wei ${ }^{1}$, Maolin Yang ${ }^{1} \&$ Guifang $\mathrm{Fu}^{1}$ \\ ${ }^{1}$ School of Public Administration, Guangdong University of Foreign Studies, Guangzhou, China \\ Correspondence: Fu Guifang, School of Public Administration, Guangdong University of Foreign Studies, \\ Guangzhou, China. E-mail: gffu@163.com
}

Received: April 29, 2019

Accepted: May 22, 2019

Online Published: May 27, 2019

doi:10.5539/ijps.v11n2p88

URL: https://doi.org/10.5539/ijps.v11n2p88

\begin{abstract}
With the rapid development of science and technology, electronic payment platforms have become increasingly mature, and network consumption has become increasingly popular. As a special consumer group, more and more college students tend to become addicted to online shopping. This study examines the probability and difference of 183 college students' online shopping addiction, and puts forward the strategies to cope with it from four perspectives: individual, family, school and society. The results showed that $62.8 \%$ of college students were addicted to online shopping. There were significant gender differences in the sub-dimensions of excessive consumption, impaired function, truncation reaction and online shopping pleasure, and women scored higher than men. There are significant grade differences in the dimension of excessive consumption and functional impairment of online shopping addiction. The excessive consumption of freshmen is significantly higher than that of other grades. The scores of functional impairment dimension of freshmen and sophomores are significantly higher than that of other grades.
\end{abstract}

Keywords: college students, online shopping, online shopping addiction

\section{Introduction}

Today online shopping is highly developed. A survey found approximately $80 \%$ of Americans has shopped online (Smith \& Anderson, 2016). And more than $80 \%$ of college students in China have the habit of online shopping (Zhu Y. et al., 2018). Online shopping brings convenience to college students, but it also has some adverse effects. For example, in order to obtain satisfaction, they constantly increase the degree, time and investment of online shopping, and use online shopping as a way to avoid problems or alleviate bad emotions. In addition, too much online shopping will seriously affect daily life and social functions (Rose S., Dhandayudham A., 2014). Zhu. et al. (2018) found that the probability of college students' online shopping addiction were $22.7 \%$ in China, and 29.5\% were addicted to online networking sites/platforms (SNS) in Singapore (Catherine So-kum Tang et al., 2017). So this study aimed to explore the current situation and the causes of the online shopping addiction of college students and to seek countermeasures to improve college students addicted to online shopping behavior, and provide a basis for the development of college students' mental health education.

Online shopping addiction (OSA) behavior refers to the tendency of an individual's inability to control their online shopping (Jiang Z. et al., 2014). Koran (2006) defines OSA as recurrent Internet shopping leads to periodic or chronic addiction, as well as uncontrollable online shopping desire; due to the tension and resistance of shopping time and frequency response, the dependence on online shopping pleasure in psychology and physiology has a continuous dependence. People who are OSA tempt to buy a lot of things that they don't need, but they are difficult to control themselves in the virtual space. The possible reason is that they usually live and work under pressure, and use this as a way to vent. This inertial behavior evolves into a "forced behavior". Research shows that the current online shopping for college students has four characteristics of increasing scale, decreasing price sensitivity, widespread social online shopping, and discount information consumption (Zhu Yanchun et al., 2018). 


\section{Methods}

\subsection{Participants}

183 college students were tested. Among them there are 54 males and 129 females. They come from different grades and majors. The specific conditions of the participants are shown in Table 1.

Table 1. Participants.

\begin{tabular}{llll}
\hline \multirow{3}{*}{ Gender } & & $n$ & Percentage \\
& male & 54 & $29.51 \%$ \\
& Female & 129 & $70.49 \%$ \\
\multirow{3}{*}{ Grade } & Freshman(1) & 52 & $28.42 \%$ \\
& Sophomore(2) & 97 & $53.01 \%$ \\
& Junior(3) & 16 & $8.74 \%$ \\
& Senior(4) & 12 & $6.56 \%$ \\
\multirow{5}{*}{ Profession } & Graduate\& above(5) & 6 & $3.24 \%$ \\
& Science\&engineering & 65 & $35.52 \%$ \\
& Literature\&history philosophy & 36 & $19.67 \%$ \\
& Economic management & 60 & $32.79 \%$ \\
& Art and sports & 6 & $3.28 \%$ \\
& Medical class & 16 & $8.74 \%$ \\
\hline
\end{tabular}

\subsection{Instruments}

This study used the student OSA questionnaire compiled by Xu L. (2014). The questionnaire consisted of 22 questions and used a 5- point Likert-type scale, including functional impairment, over-consumption, withdrawal response, and online shopping pleasure. Functional impairment (FI) refers to the social function damage caused by online shopping addiction and physical diseases, such as poor interpersonal relationship, mouse hand, frozen shoulder, etc.. Over-consumption (OC) means that consumers' shopping desire is far greater than their actual needs. Withdrawal responsiveness (WR) refers to the adverse reactions generated by consumers when external factors prevent shopping. The definition of online shopping pleasure (OSP) is the pleasure of online shopping. The reliability and validity of the questionnaire are good, the alpha coefficient is 0.942 , the alpha coefficient of each sub-dimension is $0.897 ; 0.872 ; 0.843 ; 0.633$, and the split-half reliability is 0.931 . $\mathrm{KMO}$ value was 0.934 and Bartlett spherical test was significant $(\mathrm{p}<0.001)$.

Statistical software SPSS20.0 was used for statistical analysis.

\section{Results}

\subsection{The Basic Situation of College Students' Online Shopping Addiction Tendency}

The total score of this scale is 110 points. The total score of college students is above 88 points, accounting for $23.50 \%$, and the total score is between 66 and 88 , accounting for $39.34 \%$. It can be seen that the rate of addiction is high, accounting for $62.84 \%$ of the total. The total score was $34-66$, which accounted for $30.05 \%$. There were 13 subjects whose score was lower than 44 , accounting for $7.11 \%$. Among the four sub-dimensions of online shopping addiction, the scores from high to low are excessive consumption, functional damage, online shopping pleasure and truncation response.

Table 2. Basic situation of college students' OSA.

\begin{tabular}{lcl}
\hline & $\mathrm{M}$ & $\mathrm{SD}$ \\
\hline Over spending & 18.99 & 0.40 \\
Functional damage & 18.75 & 0.32 \\
Truncated reaction & 17.78 & 0.30 \\
Online shopping pleasure & 17.84 & 0.36 \\
Online shopping addiction & 72.28 & 1.19 \\
\hline
\end{tabular}




\subsection{Gender, Grade, and Professional Differences in College Students' OSA}

The results showed that there was no professional difference in OSA, and the gender and grade differences were significant. The results are shown in Table 3.

Table 3. Gender and grade difference of OSA.

\begin{tabular}{lllllllllll}
\hline & \multicolumn{9}{c}{$M \pm S D$} & \multicolumn{3}{c}{$p$} \\
\hline & gender & & & \multicolumn{3}{c}{ grade } & & gender & grade \\
& female & male & 1 & 2 & 3 & 4 & 5 & & \\
\hline OC & $21.44 \pm$ & $18.11 \pm$ & $19.58 \pm$ & $18.70 \pm$ & $18.17 \pm$ & $20.36 \pm$ & $17.17 \pm$ & \multirow{2}{*}{$0.002^{* *}$} & $0.041^{* *}$ \\
& 6.69 & 5.08 & 6.01 & 5.36 & 5.42 & 6.67 & 8.06 & & \\
FI & $19.98 \pm$ & $18.30 \pm$ & $19.76 \pm$ & $18.19 \pm$ & $18.44 \pm$ & $20.14 \pm$ & $15.67 \pm$ & $0.019^{* *}$ & $0.176^{* *}$ \\
& 5.17 & 4.20 & 4.71 & 4.36 & 3.91 & 4.09 & 5.99 & & \\
WR & $19.04 \pm$ & $17.32 \pm$ & $18.55 \pm$ & $17.07 \pm$ & $18.00 \pm$ & $19.57 \pm$ & $17.33 \pm$ & $0.013^{* *}$ & 0.979 \\
& 4.50 & 4.02 & 4.59 & 4.08 & 4.34 & 4.09 & 5.78 & & \\
OSP & $19.37 \pm$ & $17.29 \pm$ & $18.45 \pm$ & $17.29 \pm$ & $17.78 \pm$ & $19.21 \pm$ & $18.33 \pm$ & $0.011^{* *}$ & 0.907 \\
& 5.62 & 4.87 & 4.90 & 5.20 & 5.24 & 5.26 & 6.48 & & \\
OSA & $79.83 \pm$ & $71.04 \pm$ & $76.34 \pm$ & $71.25 \pm$ & $72.39 \pm$ & $79.29 \pm$ & $68.50 \pm$ & $0.002^{* *}$ & 0.623 \\
& 20.93 & 16.58 & 18.64 & 17.43 & 17.58 & 18.76 & 25.45 & & \\
\hline
\end{tabular}

$* \mathrm{p}<0.05$.

** $\mathrm{p}<0.01$.

As can be seen from Table 3, college students have significant gender differences in OC, FI, WR, OSP, and OSA, and women score significantly higher than men.

College students have significant grade differences in the dimension of OC and FI. After multiple comparisons by LSD, the scores of the $\mathrm{OC}$ of the first grade are significantly higher than those of other grades; the scores of the FI of the freshman and sophomore grades are significantly higher than those of the other grades.

\subsection{Regression Analysis of Dimensions of College Students' Online Shopping Addiction}

In order to better predict the tendency of college students to become addicted to online shopping, and propose corresponding solutions, we did a regression analysis of different dimensions of college students' OSA. The results are shown in Table 4.

Table 4. Regression Analyses of OSA.

\begin{tabular}{lllllll}
\hline & \multirow{2}{*}{$\mathrm{R}^{2}$} & $\mathrm{~F}$ & $\mathrm{p}$ & \multicolumn{2}{l}{$\beta$} & \\
\cline { 5 - 6 } & & & & gender & grade \\
\hline Over spending & 0.069 & 4.927 & $0.003^{* *}$ & -0.260 & -0.044 \\
Functional damage & 0.037 & 2.550 & 0.057 & & \\
Truncated reaction & 0.030 & 2.096 & 0.102 & & \\
Online shopping pleasure & 0.032 & 2.192 & 0.090 & & \\
Online shopping addiction & 0.047 & 3.310 & $0.021^{* *}$ & -0.215 & -0.037 \\
\hline
\end{tabular}

From Table 4, Dummy variables can explain $4.9 \%$ of OSA variation, $(\mathrm{f}=3.310, p<0.05)$, and have a predictive effect on OSA. The gender dummy variable $\beta$ is -0.215 and the coefficient is negative, indicating that women are more likely to become addicted to online shopping. Grade dummy variables $\beta$ is -0.037 , indicating low-grades than high-grade easier OSA. The dummy variable can explain $6.9 \%$ of the OC variation, and is significant $(\mathrm{f}=4.927, p<0.05$ ), which has a predictive effect on OC. The gender dummy variable $\beta$ is -0.260 and the coefficient is negative, indicating that women are more likely to OC. The graded dummy variable $\beta$ is -0.044 and the coefficient is negative, indicating that the lower grades are more prone to OC than the upper grades. 


\section{Discussions}

\subsection{College Students Are Seriously Addicted to Online Shopping, Especially Girls.}

This study found that $62.8 \%$ of college students were addicted to online shopping and excessive consumption is the best predictor of online shopping addiction. There are gender differences in online shopping addiction, female addiction is significantly higher than male addiction, which is consistent with Shi Q., Fu A. (2016). This may be because women have a greater demand for online shopping, such as cosmetics and clothes. Wang D. (2017) also found that there is gender difference of online shopping and female college students' total score of online shopping habits are significantly higher than male college students.

\subsection{Reasons for OSA}

The convenience of online shopping is an important reason for college students' online shopping addiction. Compared to physical store shopping, online shopping allows college students to quickly purchase the items they want, no matter where they are. At present, the rapid development of China's e-commerce platforms such as Taobao, Jingdong, Dangdang and Vipshop will further enhance the convenience of online shopping. Another advantage for online shopping is low price. Online shopping enables college students to spend less money and buy the same goods.

From a personal perspective, weak self-control ability of college students is a major cause of OSA. This study found that most college students would have excessive consumption in daily online shopping. After enjoying the "sweetness" of online shopping, college students who lack strong self-control tend to continue to indulge in online shopping, which leads to a tendency to become addicted to online shopping. This finding is consistent with the conclusion of Wang D. (2017).

Online shopping is also a way for college students to relieve their pressure. With the rapid development of society, college students are facing increasing pressures, including academic, interpersonal and employment pressures. Online shopping will indeed bring pleasant psychological experience to college students and relieve their pressure.

Zheng M.'s study (2013) suggested that online shopping provides an invisible social support system for college students, especially for college students who are relatively introverted and have relatively few friends. In addition, Zheng $\mathrm{M}$. also found that the rate of OSA among college students with a small number of friends (34.88\%) was much higher than that of college students (13.78\%). The invisible social support system established by the online shopping platform enables college students to meet their needs in the consumption process.

Social ethos is also affecting the formation of college students' OSA. With the improvement of people's living standards, people are no longer satisfied with the practical-oriented utilitarian consumption concept, but begin to turn to the hedonistic consumption concept. The hedonistic social atmosphere is likely to cause comparison and herd consumption psychology, and increase the phenomenon of online shopping addiction.

\subsection{Coping Strategies}

Compulsive buying has brought many negative effects to college students (Müller A. et al, 2014), including wasting time, reducing academic performance and increasing financial burden etc. De Zwaan (2011) found many patients with compulsive suffer from comorbid psychiatric disorders, especially anxiety, depression, binge eating disorder, substance use disorders and obsessive-compulsive disorder etc. $\mathrm{CB}$ is associated with mounting tension, general distress and lower quality of psychological well-being (Williams A. D., 2012). Therefore, students themselves, parents, experts in relevant disciplines and society should attach great importance to the problem of online shopping addiction of college students, and explore countermeasures to reduce online shopping addiction.

College students should enhance their self-control ability and find healthy ways to vent their emotions. College students should realize that the main task of college is to learn and develop themselves, and should not pay too much attention to shopping. Therefore, college students themselves should timely reflect on their consumption needs and the rationality of online consumption behavior, and try to control their excessive consumption behavior. For example, college students can conduct mindfulness training and exercise regularly every day to shift their attention to other things.

College students should set up correct consumption concept. College students should pay attention to cultivating their correct consumption concept and avoid irrational consumption such as vanity, comparison and conformity. As a new force of social development, college students should set up a modern concept of green consumption, but occupy and waste too much resource. 
Parents should guide college students' consumption concepts and behaviors. College students' life experience is insufficient, and they are vulnerable to the influence of promotional information and discount information, which leads to unnecessary consumption, which requires parents to give correct guidance to consumption. Especially in China's social environment, most college students do not work part-time and depend on their parents' supply economically, so parents need to guide their children's scientific consumption more.

Schools should provide psychological counseling on College Students' consumption addiction. Schools and teachers should also communicate with college students in time, do a good job in psychological education and counseling, and avoid serious psychological problems and mental illnesses caused by excessive consumption of College students. For example, the school should set up a special group psychological counseling course for female college students to prevent and intervene the problem of online shopping addiction in time.

In addition, psychologists, sociologists and economists should strengthen the study of the psychological mechanism of online shopping addiction, especially the brain mechanism, find out the scientific principles of preventing, controlling and intervening online shopping addiction, and establish a set of practical methods of self-prevention and control of online shopping addiction for college students.

\section{Conclusion}

This study investigated the status quo, gender differences, grade differences and professional differences of College Students' online shopping addiction by questionnaire. It found that the problem of College Students' online shopping addiction was serious, especially female students. It also discussed the causes and Countermeasures of College Students' online shopping addiction. This study found that more than $60 \%$ of college students are addicted to online shopping, female college students are significantly higher than male college students in online shopping addiction and its sub-dimensions of excessive consumption, functional damage, truncation response, online shopping pleasure; freshman students' excessive consumption is significantly higher than other grades; freshman and sophomore students' functional damage dimension are significantly higher than other grades. This research discovers college students' consumption tendency and problems in time, which needs to arouse the attention of parents, schools and society. This research has strong social practical significance and theoretical value. Future research should use experimental method to further investigate the psychological mechanism of College Students'online shopping addiction, and establish operational procedures for prevention and intervention of online shopping addiction.

\section{References}

Catherine So-kum Tang., Yvaine Yee Woen Koh. (2017). Online social networking addiction among college students in Singapore: Comorbidity with behavioral addiction and affective disorder, Asian Journal of Psychiatry, 25, 175-178. https://doi.org/10.1016/j.ajp.2016.10.027

CNNIC. (2016). 2015 China's online shopping market research report. Beijing: China Internet Network Information Center. 2016 -06 -23. http://www.199it.com/archives/487026.html

de Zwaan, M. (2011). Psychiatric comorbidity and compulsive buying disorder. In: Müller, A., Mitchell, J.E. (Eds.), Compulsive Buying: Clinical Foundations and Treatment. Routledge, Taylor \& Francis Group, New York, 87-104

Du Y. (2016). Research on the Impact of Third-Party Payment Methods on Consumers' Product Information Perception and Purchase Behavior. Jiangxi Normal University. http://kns.cnki.net/KCMS/detail/detail.aspx

Jiang Z., Zhao X., Li C. (2017). Self-control predicts attentional bias assessed by online shopping -related Stroop in high online shopping addiction tendency college students. Comprehensive Psychiatry, 75, 14-21. https://doi.org/10.1016/j.comppsych.2017.02.007

Koran LM; Faber RJ; Aboujaoude E; Large MD; Serpe RT. (2006). Estimated prevalence of compulsive buying behavior in the United States. The American Journal Of Psychiatry, 10, 1806-1812. https://doi.org/10.1176/ajp.2006.163.10.1806

Liu L. (2014). College Students' Internet Shopping Addiction Behavior and Psychological Guidance Education. Literature Education, 4, 134-135.

Müller, Astrid; Claes, Laurence; Georgiadou, Ekaterini; Möllenkamp, Maike; Voth, Eva M; Faber,Ron J; Mitchell, James E; de Zwaan, Martina. (2014). Is compulsive buying related to materialism, depression or temperament? Findings from a sample of treatment-seeking patients with CB. Psychiatry research, 1, 103-107. https://doi.org/10.1016/j.psychres.2014.01.012

Rose S, Dhandayudham A. (2014). Towards an understanding of internet-based problem shopping behavior: the 
concept of online shopping addiction and its proposed predictors. Journal of Behavioral Addictions, 3, 83-9. https://doi.org/10.1556/JBA.3.2014.003

Shi Q., Fu A.. (2016). The Present Situation and Countermeasures of College Students' Online Shopping $\begin{array}{lllll}\text { Addiction Tendency. } \quad \text { Contemporary } & \text { Youth research, } & \text { 2, }\end{array}$ https://doi.org/10.3969/j.issn.1006-1789.2016.02.002

Smith, A., \& Anderson, M. (2016). Online shopping and e-Commerce. Retrieved from Pew Research Center website. http://www.pewinternet.org/2016/12/19/online- shopping-and-e-commerce/.

Tao Sun, Guohua Wu. (2011). Trait Predictors of Online Impulsive Buying Tendency: A Hierarchical Approach. Journal of Marketing Theory \& Practice, 3, 337-346. https://doi.org/10.2753/MTP1069-6679190307

Wang D. (2017). The relationship between college students' self-control and online shopping addiction. (Master's thesis, Wuhan University, 2017)

Williams, A.D. (2012). Quality of life and psychiatric work impairment in compulsive buying: increased symptom severity as a function of acquisition behaviors. Comprehensive Psychiatry, 53(6), 822-828. https://doi.org/10.1016/j.comppsych.2011.11.001

Xu L. (2014). A Preliminary Study about Online Shopping Addiction of University Students and Questionnaire Compilation. (Master's thesis, Central China Normal University , 2014).

Yan J. (2018). Investigation on College Students' Online Shopping Addiction in Guangzhou, Science and Education Collection (Later Periodicals), 2, 161-162.

Zheng M.. (2013). College students' online shopping addiction phenomenon and coping strategies. (Master's thesis, Hunan University).

Zhu Y., Li N. (2018). Analysis of the Status Quo of College Students' Online Shopping in the New Normal Period. China Market, 967, 194-196.

Zhu Y., Gao X. \& Li R. (2015). An investigation on undergraduate's online shopping addiction, Journal of Liaoning Technical university (social science Edition), 6, 634-635. https://doi.org/10.11955/j.issn.1008-391x.20150613

\section{Copyrights}

Copyright for this article is retained by the author(s), with first publication rights granted to the journal.

This is an open-access article distributed under the terms and conditions of the Creative Commons Attribution license (http://creativecommons.org/licenses/by/4.0/). 